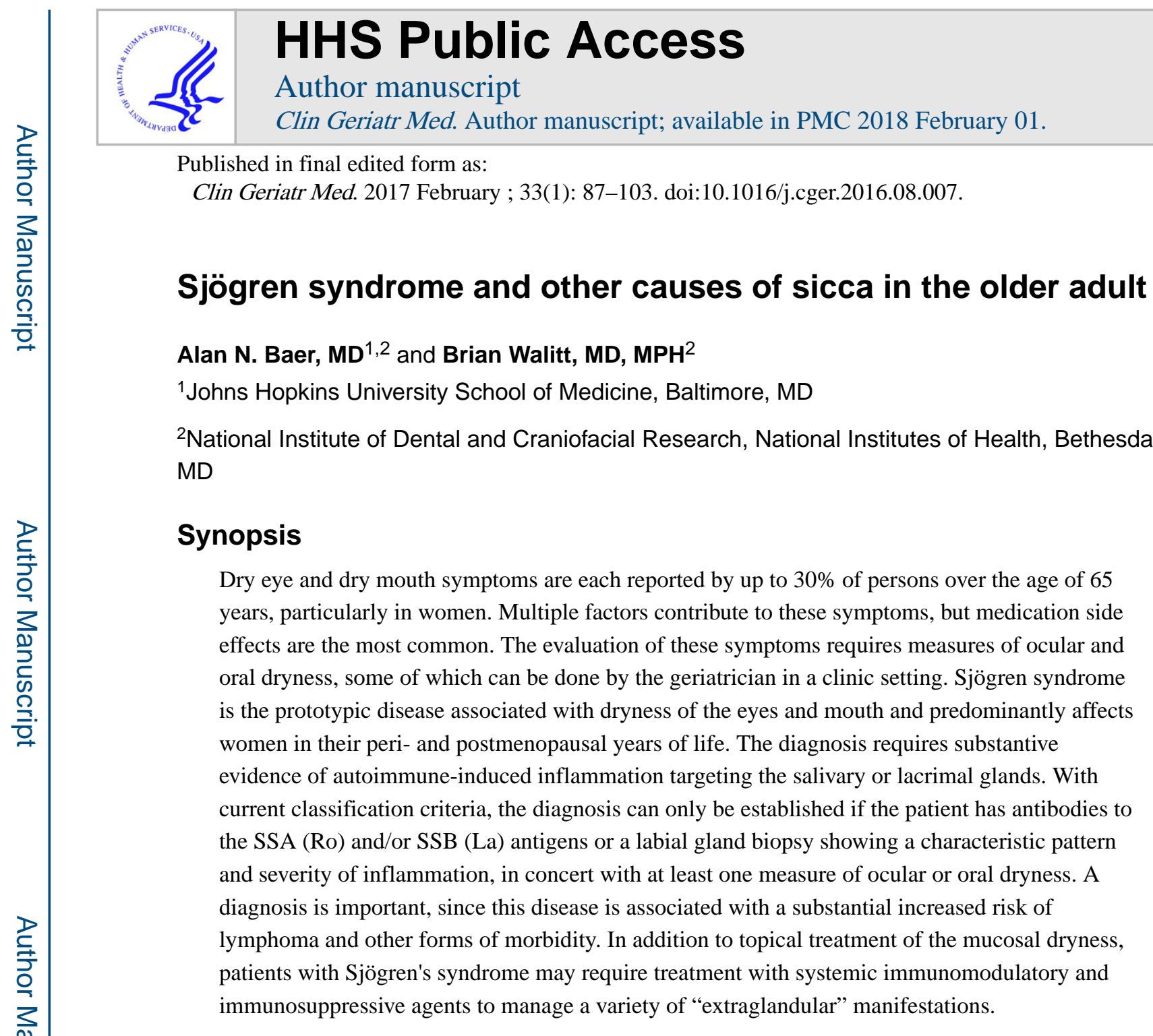

Keywords

Sjögren's syndrome; dry eye; aging; salivary hypofunction; xerostomia

\title{
Introduction
}

Symptoms of dryness of the eyes, mouth, and vagina (in women) are common among the elderly and have a substantial impact on life quality. The prevalence of these symptoms increases with age and reaches up to $30 \%$ in persons over the age of 65 years, particularly in women [1-5]. Objective evidence of diminished tear or saliva production is much less

Corresponding Author: Alan N. Baer, MD, 5200 Eastern Avenue, Suite 4000, Mason Lord Center Tower, Baltimore, MD 21224 alanbaer@jhmi.edu; Brian Walitt, MD, MPH, National Institute of Dental and Craniofacial, Research, 10 Center Drive, Bethesda, MD 20892.

Disclosure Statement: The authors have nothing to disclose

Publisher's Disclaimer: This is a PDF file of an unedited manuscript that has been accepted for publication. As a service to our customers we are providing this early version of the manuscript. The manuscript will undergo copyediting, typesetting, and review of the resulting proof before it is published in its final citable form. Please note that during the production process errors may be discovered which could affect the content, and all legal disclaimers that apply to the journal pertain. 
frequent [4-6], indicative of the weak association between dryness symptoms and objective measures. There are many potential causes for mucosal dryness in the elderly, and multiple factors can contribute in a single individual.

Sjögren syndrome (SS) is a chronic systemic autoimmune disease characterized by dry eyes and dry mouth, arising from autoimmune-induced inflammation of the lacrimal and salivary glands. It primarily affects peri- and postmenopausal women and is a prime diagnostic consideration in an older patient with mucosal dryness. It can occur in a primary form or in association with another systemic autoimmune disease (labeled secondary SS). The reported prevalence of primary SS in population-based studies ranges from 0.01-0.09\% [7]. SS is present in up to $17 \%$ of patients with rheumatoid arthritis [8,9], a disease whose prevalence reaches $1.1 \%$ in the United States [10]. Thus, the overall prevalence is higher, making SS the second most common systemic rheumatic disease.

In this chapter, the authors will review the clinical manifestations, differential diagnosis, and medical evaluation of the elderly patient with dry eyes and mouth, as well as the approach to the diagnosis and management of SS.

\section{Dry eye}

Dry eye manifests most often with ocular irritation, including burning, stinging, soreness, and a foreign body sensation. The symptoms are aggravated by exposure to low humidity, wind or air drafts, as well as prolonged visual attention, including reading. Less frequent symptoms include blurred vision, excess tearing and blepharospasm.

Dry eye is generally caused by diminished tear production or by excessive tear evaporation [11] (Box 1). The former is most often due to lacrimal gland disease but can result from lacrimal gland duct obstruction or reflex hyposecretion related to corneal sensory loss. Excessive evaporation from meibomian gland dysfunction and other forms of blepharitis is more common. Other causes of dryness include incomplete lid closure during sleep, allergic conjunctivitis, and trachoma.

Tear production and lipid content have been shown to diminish with age $[12,13]$ as a result of changes in lacrimal and meibomian glands, a decreased density of conjunctival goblet cells, and somatosensory nerve impairments [14]. In addition, the elderly frequently have conditions contributing to dry eye, such as use of medications with anti-cholinergic side effects, past refractive or cataract surgery [15], lagophthalmos, blink abnormalities, and conjunctivochalasis [16].

The assessment of dry eye requires multiple tests (Box 2). The Schirmer test measures tear production [17] and can be reliably performed by a geriatrician in a clinic setting. A sterile rectangular strip of filter paper, rounded and notched at the proximal end, is folded over the lower eyelid at the midpoint between the middle and lateral fornix of each eye. The patient is then asked to close the eyes gently during the 5 minute duration of the test. The extent of tear "wicking" or wetting is recorded in millimeters and is normally greater than $5 \mathrm{~mm}$ in both eyes. The Schirmer test can be performed with or without anesthesia to measure basal and reflex tear secretion, respectively. This test is imperfect in the elderly, since the results 
decline with age. In two population-based surveys of elderly individuals (65 years or older), the prevalence of an abnormal Schirmer test ranged from $12-58 \%[2,4]$.

Ocular surface staining with vital dyes allows slit lamp visualization of devitalized conjunctival cells and corneal epithelial defects. Lissamine green is most commonly used to stain the conjunctiva and fluorescein the cornea. The extent of ocular surface staining is a measure of dryness-induced ocular surface damage, is one of the classification criteria for SS, and can be scored using methods described by van Bijsterveld and by the Sjögren's International Collaborative Clinical Alliance (SICCA) [18-20].

The tear break up time is used to assess the stability of the tear film [21] and is typically abnormal in meibomian gland dysfunction. Tear osmolarity measurement $[22,23]$ is the best for predicting dry eye severity [23].

\section{Xerostomia and salivary hypofunction}

Symptoms of dry mouth, termed xerostomia, include burning, dry lips, alteration of taste, and a sense of having an inadequate amount of saliva. There also may be difficulty speaking, swallowing and wearing dentures. The need to sip water to swallow dry food is an important marker of reduced salivary function [24]. Halitosis, painful tongue fissures, mucosal ulcers, and pain with ingestion of spicy or acidic foods are common discomforts that may stem from candidal overgrowth on the oral mucosa. The relation between salivation and xerostomia is complex. Dawes showed that healthy subjects report dry mouth symptoms when their baseline salivary flow is reduced by $50 \%$, even if the residual salivary flow level remains within the broad range of normal [25].

Saliva is produced by the major (parotid, submandibular, sublingual) and myriad submucosal minor salivary glands. The parotid glands only produce saliva upon gustatory or olfactory stimulation. Saliva is continually secreted by the sublingual, submandibular, and minor salivary glands. This basal secretion is crucial for maintaining oral health.

Both unstimulated and stimulated salivary flow rates are measured. Saliva that pools in the mouth without stimulation can be collected for 5-15 minutes, providing a measure of "whole" saliva production in a clinic setting (Box 3). It is considered the most relevant measure of oral health. Stimulated whole salivary flow rates can be measured with the patient chewing gum or pre-weighed gauze and are not generally affected by medication use. With special research techniques, stimulated (e.g. with lemon juice on the tongue) and unstimulated saliva flow rates can be measured from the individual parotid glands or sublingual/submandibular glands.

Human salivary glands undergo atrophy with age (Figure 1). In morphometric studies, aging was associated with acinar loss and replacement with fat and connective tissue [26, 27]. Whole unstimulated saliva flow rates decline with age, which may contribute to the agedependent increase in dental caries [28]. However, this is not true for stimulated parotid saliva flow rates [29]. 
There are multiple potential etiologies for xerostomia and salivary hypofunction in the elderly (Box 4) [6]. Side effects from medications commonly used in the geriatric population are the most common.

\section{Vaginal dryness}

Vaginal dryness, dyspareunia and vulvar pruritus are common symptoms among postmenopausal women. These symptoms relate to menopause-related decreases in estrogen and other sex steroids but can also have other etiologies. In 2014, two international societies recommended that the range of symptoms and signs associated with menopause be termed the "genitourinary syndrome of menopause" [30]. These symptoms include genital dryness, burning, irritation, inadequate lubrication, dyspareunia, urinary urgency, dysuria, and recurrent urinary tract infections. Similar symptoms are also seen with infectious vaginitis, irritant or allergic vulvitis or vaginitis, vulvovaginal dermatoses, hypertonic pelvic floor muscle dysfunction, painful bladder syndrome/interstitial cystitis, vulvodynia, and pudendal neuralgia [30].

In women affected by SS, vaginal dryness can be severe and impact sexual ability and pleasure [31]. There is scant information regarding the etiology of this dryness. One hypothesis is that the Skene and related glands of the vaginal introitus are affected in the same manner as exocrine glands found elsewhere [32]. There has been no histopathologic confirmation of this to date.

\section{Sjögren syndrome}

SS is the prototypic illness of dryness of the eyes and mouth. It is a systemic autoimmune disease characterized by lymphocytic infiltration of the salivary and lacrimal glands. This chronic inflammatory process gradually leads to glandular injury and related dysfunction over the course of years, eventually causing the cardinal symptoms of dry eyes and mouth. Keratoconjunctivitis sicca is the term coined by Henrik Sjögren in 1933 to describe the dry eye component of this syndrome [33]. Key features are shown in Box 5.

SS disease onset is uncommon after the age of 65 or 70 [40, 41]. Older patients with SS, when compared to younger ones, have a lower frequency of serologic abnormalities, such as anti-SSA, anti-SSB, rheumatoid factor and hyperglobulinemia [42]. Parotid enlargement, arthalgia, and Raynaud's phenomenon are also less common, while higher frequencies of lung involvement and anemia have been noted [41]. A distinct subset of older SS patients with anti-centromere antibodies is characterized by Raynaud's phenomenon, overlap features of limited systemic sclerosis, and more severe salivary and lacrimal gland dysfunction [43].

The clinical presentation of SS is varied, but is most often that of mucosal dryness (Box 6).

SS is associated with a variety of systemic manifestations (Box 7). Some are direct manifestations of the disease while others represent coincidental autoimmune diseases. Apart from symptoms of fatigue, joint pain, and mild cognitive impairment (often labeled "brain fog"), the prevalence of these organ-specific manifestations is each less than $20 \%$ [44]. 
The natural history is generally one of stability, with a slow decline in lacrimal and salivary gland function. It is not characterized by the types of disease flares seen in systemic lupus or rheumatoid arthritis, but patients may report periods of worsening sicca or fatigue. There is no increase in overall mortality according to a recent meta-analysis, but patients with specific extra-glandular manifestations, including those with vasculitis, cryoglobulinemia, pulmonary disease and lymphoma, have been identified as having higher mortality rates [45, 46].

\section{Diagnosis of Sjögren's syndrome}

The diagnosis requires evidence of autoimmune-induced inflammation targeting the salivary or lacrimal glands. Two sets of classification criteria are currently in use, the 2002 American-European Criteria Group (Box 8) and the 2012 American College of Rheumatology provisional classification criteria (Box 9) [47, 48]. Both require that the patient have either anti-SSA and/or anti-SSB antibodies or a minor salivary gland biopsy demonstrating focal lymphocytic sialadenitis with a focus score $\geq 1$. These two sets of criteria have good concordance [49]. However, both criteria sets have limitations, and thus a new set of international consensus criteria is in development. We utilize these current classification criteria as a general guide, and establish the diagnosis if a patient has an objective measure of ocular and/or oral dryness or characteristic imaging abnormalities (e.g. by ultrasound, MR or CT), coupled with anti-SSA antibodies or a positive lip biopsy.

For the practicing geriatrician, we recommend that a patient suspected of having SS be evaluated as follows:

- $\quad$ History, seeking a history of persistent symptoms of dry eyes and/or mouth. Validated screening questions are included in the American European Classification Criteria (Box 8)

- $\quad$ Examination, seeking signs of salivary hypofunction and of a systemic rheumatic disease

- $\quad$ Oral examination

- Is there enlargement of the lacrimal or major salivary glands? What is the texture of the major salivary glands? Are there discrete nodules or masses?

- Does saliva pool under the elevated tongue when observed over the course of one minute?

- Does the tongue have deep fissures, a hyperlobulated appearance, or absence of filiform papillae on its surface?

- $\quad$ General examination 
Look for sclerodactyly, palpable purpura, synovitis, basilar pulmonary rales

- $\quad$ Laboratory testing

Screen for ANA (tested by immunofluorescence assay), anti-SSA (Ro), and anti-SSB (La), and rheumatoid factor. Anti-SSA and anti-SSB antibodies can be present despite a negative ANA test.

A CBC, urinalysis, and chemistry profile may reveal abnormalities supportive of SS, including leucopenia and neutropenia, hyperglobulinemia, renal impairment, and proteinuria.

- Ophthalmologic examination

- $\quad$ Schirmer testing is an appropriate initial test. A formal ophthalmologic examination will serve not only to confirm the diagnosis of dry eye but also define the contributing causes, such as meibomian gland dysfunction, conjunctivochalasis, etc. Guidelines for this evaluation can be found at https://sicca-online.ucsf.edu/documents/eyeexam-SOP.pdf

- $\quad$ Sialometry.

Documentation of salivary hypofunction is only necessary if the eye examination does not show dry eye disease (Box $3)$.

- $\quad$ Labial gland biopsy

A labial gland biopsy, best performed by an oral surgeon, is required for diagnosis if the patient lacks anti-SSA and/or anti-SSB antibodies. The biopsy also has value in excluding alternative diagnoses (such as sarcoid, amyloid, MALT lymphoma and IgG4-related disease). Guidelines for its performance can be found at https://siccaonline.ucsf.edu/documents/Oral-Saliva-SOP.pdf.

- $\quad$ Imaging (Figure 2)

- $\quad$ Salivary gland ultrasonography is favored due to its lower cost and lack of ionizing radiation. The presence of multiple ovoid hypoechoic lesions, often bounded by hyperechoic bands, correlates with markers of more severe disease. These imaging abnormalities have high specificity for the diagnosis, but only moderate sensitivity [50-54].

- $\quad$ CT imaging is not recommended because of the radiation exposure. However, the presence of multiple punctate 
calcifications within the parotid glands has high specificity [55].

MR imaging of the parotid glands may reveal heterogeneity of signal intensity on both T1- and T2weighted images, with both hypointense and hyperintense foci measuring 1-4 $\mathrm{mm}$ in diameter [56].

Be aware of certain common pitfalls in the diagnostic evaluation. Antibodies to SSA and SSB are not specific. They are frequently found in systemic lupus and inflammatory myopathies and are seen in up to $0.9 \%$ of healthy women in the US population [57]. Labial gland biopsies of older adults are also subject to misinterpretation. The histopathology of the minor salivary gland, termed "focal lymphocytic sialadenitis", is characterized by lymphocytic aggregates which surround intralobular salivary ducts (Figure 3) and are adjacent to normal-appearing mucous-secreting acini. The number of these lymphocytic aggregates per $4 \mathrm{~mm}^{2}$ of glandular tissue section equates to the "focus score". A score $\geq 1$ is a criterion for the classification of SS and has been validated as the best cut-off value differentiating SS from non-SS controls [58]. Since chronic inflammation of the salivary gland can also arise from ductal obstruction and other forms of glandular injury, care must be taken to exclude from the focus score lymphocytic aggregates in areas of severe acinar loss, ductal dilatation, and fibrosis (Figure 4).

In the elderly patient, the differential diagnosis of SS primarily includes alternative causes of sicca symptoms, salivary and/or lacrimal gland enlargement, and the characteristic serologic abnormalities.

- $\quad$ Sicca complex in the elderly. Age-related interstitial fibrosis, acinar atrophy and nonspecific chronic inflammation in the labial gland biopsy may be misinterpreted as indicative of SS (Figure 4).

- $\quad$ Salivary and/or lacrimal gland enlargement. In the elderly patient, particular attention should be paid to the possibility of lymphoma. IgG-4 related disease is more common in elderly men. It may present as unilateral submandibular gland enlargement (Köttner tumor) or parotid and lacrimal gland enlargement. Other diagnostic possibilities include amyloid infiltration, sarcoidosis, HIV infection, bulimia, and hyperlipoproteinemia.

- $\quad$ Serologic abnormalities. Antinuclear antibodies, rheumatoid factor and monoclonal proteins, are more prevalent in the elderly population [57]. Thus, positive tests must be interpreted cautiously when they happen to coincide with symptoms or signs of oral or ocular dryness.

\section{Management of Sjögren's syndrome}

The majority of patients only require topical and systemic treatments directed at alleviating their ocular, oral, and vaginal dryness, preventing dental decay, and managing oral candidiasis. Patients with systemic manifestations, including those with joint pain, skin 
lesions, and internal organ involvement, may benefit from immunomodulatory treatments. All SS patients require monitoring for disease complications, especially lymphoma.

Management of ocular dryness depends on its severity and the patient's response to therapy [59]. Avoidance of wind and smoke and protective eyewear can be helpful for all patients. Artificial tears with a demulcent (such as methylcellulose, propylene glycol and glycerine) are a mainstay of treatment. Patients should use preservative-free drops if drops are instilled four or more times a day. Use of thicker ocular gels and ointments before bed can help with dryness that occurs during sleep. Supplementation of the diet with omega-3 essential fatty acids has been shown to be of benefit. Use of topical cyclosporine and steroid solutions can be useful in a variety of dry eye conditions but should be undertaken in consultation with an ophthalmologist. Punctal plugs to preserve tears are often used in moderate to severe dry eye. Patients with more severe dry eye disease may require the use of moisture chamber spectacles, autologous serum tears, contact lenses or scleral prostheses.

Prevention of oral dryness includes maintaining good hydration and avoiding medications that worsen dryness. Patients should be counseled to be more aware of factors that can aggravate dryness, such as low humidity environments and mouth breathing. Frequent sips of oral solutions can be helpful, with options ranging from water to artificial saliva. Sucking on sugar-free hard candies helps stimulate saliva flow. Oral hygiene and dental care are essential in preserving dentition in persons with pathological oral dryness.

Muscarinic agonists, such as pilocarpine and cevimeline, can substantially increase saliva and to a lesser extent tear flow. However, overall tolerance of these agents may be hampered by cholinergic side effects of excessive sweating, increased urinary frequency, flushing, chills, rhinitis, nausea, and diarrhea. Care must be taken when with these medications are prescribed to the elderly.

Vaginal moisturizers and lubricants, including olive and vitamin $\mathrm{E}$ oils are initial treatment options for vaginal dryness. Vitamin E capsules can be opened and the oil used in and around the vagina. A suppository containing hyaluronic acid, vitamin E, and vitamin A, used once daily for 14 days, then once every other day for the next two weeks, can be effective [60]. Obtaining these suppositories requires a compounding pharmacist. Topical estrogen cream may help if symptoms do not improve with these other measures.

Hydroxychloroquine is commonly used for the management of joint pain and/or fatigue. However, clinical trials with this drug have shown mixed results, with none showing major clinical improvements [61-63]. The effect of immunosuppressive therapies on the glandular manifestations has been disappointing to date. The effect of rituximab on SS dryness is still being evaluated, with potential benefit being observed in a small double-blind placebocontrolled trial [64] but not in a larger one [65]. Prolonged therapy may be required for benefit [66].

\section{Conclusion}

Dryness of the eyes and mouth is a prevalent symptom among the elderly, most often related to the side effects of medications. However, there is a broad differential diagnosis for each 
symptom, and careful evaluation is important to define the etiology and correct treatment. SS is the prototypic disease that leads to these symptoms and primarily affects perimenopausal women. The diagnosis requires demonstration of an autoimmune disease underlying the sicca manifestations, either serologically or pathologically. Management can involve both topical and systemic therapies.

\section{Acknowledgments}

This manuscript was supported [in part] by the Intramural Research Program of the NIH, NIDCR

\section{References}

1. Johansson AK, Johansson A, Unell L, et al. Self-reported dry mouth in Swedish population samples aged 50, 65 and 75 years. Gerodontology. 2012; 29(2):e107-15. [PubMed: 22050189]

2. Lin PY, Tsai SY, Cheng CY, et al. Prevalence of dry eye among an elderly Chinese population in Taiwan: the Shihpai Eye Study. Ophthalmology. 2003; 110(6):1096-101. [PubMed: 12799232]

3. Billings RJ, Proskin HM, Moss ME. Xerostomia and associated factors in a community-dwelling adult population. Community Dent Oral Epidemiol. 1996; 24(5):312-6. [PubMed: 8954216]

4. Schein OD, Munoz B, Tielsch JM, et al. Prevalence of dry eye among the elderly. Am J Ophthalmol. 1997; 124(6):723-8. [PubMed: 9402817]

5. Hay EM, Thomas E, Pal B, et al. Weak association between subjective symptoms or and objective testing for dry eyes and dry mouth: results from a population based study. Ann Rheum Dis. 1998; 57(1):20-4. [PubMed: 9536818]

6. Liu B, Dion MR, Jurasic MM, et al. Xerostomia and salivary hypofunction in vulnerable elders: prevalence and etiology. Oral Surg Oral Med Oral Pathol Oral Radiol. 2012; 114(1):52-60. [PubMed: 22727092]

7. Qin B, Wang J, Yang Z, et al. Epidemiology of primary Sjögren's syndrome: a systematic review and meta-analysis. Ann Rheum Dis. 2015; 74(11):1983-9. [PubMed: 24938285]

8. Uhlig T, Kvien TK, Jensen JL, et al. Sicca symptoms, saliva and tear production, and disease variables in 636 patients with rheumatoid arthritis. Ann Rheum Dis. 1999; 58(7):415-22. [PubMed: 10381485]

9. Carmona L, Gonzalez-Alvaro I, Balsa A, et al. Rheumatoid arthritis in Spain: occurrence of extraarticular manifestations and estimates of disease severity. Ann Rheum Dis. 2003; 62(9):897-900. [PubMed: 12922967]

10. Gabriel SE, Crowson CS, O'Fallon WM. The epidemiology of rheumatoid arthritis in Rochester, Minnesota, 1955-1985. Arthritis Rheum. 1999; 42(3):415-20. [PubMed: 10088762]

11. The definition and classification of dry eye disease: report of the Definition and Classification Subcommittee of the International Dry Eye WorkShop (2007). Ocul Surf. 2007; 5(2):75-92. [PubMed: 17508116]

12. HENDERSON JW, PROUGH WA. Influence of age and sex on flow of tears. Arch Ophthal. 1950; 43(2):224-31.

13. Mathers WD, Lane JA, Zimmerman MB. Tear film changes associated with normal aging. Cornea. 1996; 15(3):229-34. [PubMed: 8713923]

14. Gipson IK. Age-related changes and diseases of the ocular surface and cornea. Invest Ophthalmol Vis Sci. 2013; 54(14):ORSF48-53. [PubMed: 24335068]

15. Kasetsuwan N, Satitpitakul V, Changul T, et al. Incidence and pattern of dry eye after cataract surgery. PLoS One. 2013; 8(11):e78657. [PubMed: 24265705]

16. Chhadva P, Alexander A, McClellan AL, et al. The impact of conjunctivochalasis on dry eye symptoms and signs. Invest Ophthalmol Vis Sci. 2015; 56(5):2867-71. [PubMed: 26024073]

17. Cho P, Yap M. Schirmer test. I. A review. Optom Vis Sci. 1993; 70(2):152-6. [PubMed: 8446379]

18. van Bijsterveld OP. Diagnostic tests in the Sicca syndrome. Arch Ophthalmol. 1969; 82(1):10-4. [PubMed: 4183019] 
19. Whitcher JP, Shiboski CH, Shiboski SC, et al. A simplified quantitative method for assessing keratoconjunctivitis sicca from the Sjögren's Syndrome International Registry. Am J Ophthalmol. 2010; 149(3):405-15. [PubMed: 20035924]

20. Bron AJ, Evans VE, Smith JA. Grading of corneal and conjunctival staining in the context of other dry eye tests. Cornea. 2003; 22(7):640-50. [PubMed: 14508260]

21. Sweeney DF, Millar TJ, Raju SR. Tear film stability: a review. Exp Eye Res. 2013; 117:28-38. [PubMed: 23973716]

22. Lemp MA, Bron AJ, Baudouin C, et al. Tear osmolarity in the diagnosis and management of dry eye disease. Am J Ophthalmol. 2011; 151(5):792-798.e1. [PubMed: 21310379]

23. Potvin R, Makari S, Rapuano CJ. Tear film osmolarity and dry eye disease: a review of the literature. Clin Ophthalmol. 2015; 9:2039-47. [PubMed: 26586933]

24. Fox PC, Busch KA, Baum BJ. Subjective reports of xerostomia and objective measures of salivary gland performance. J Am Dent Assoc. 1987; 115(4):581-4. [PubMed: 3477595]

25. Dawes C. Physiological factors affecting salivary flow rate, oral sugar clearance, and the sensation of dry mouth in man. J Dent Res. 1987; 66 Spec No:648-53. [PubMed: 3476629]

26. Scott J, Flower EA, Burns J. A quantitative study of histological changes in the human parotid gland occurring with adult age. J Oral Pathol. 1987; 16(10):505-10. [PubMed: 3127564]

27. Syrjanen S. Age-related changes in structure of labial minor salivary glands. Age Ageing. 1984; 13(3):159-65. [PubMed: 6731173]

28. Percival RS, Challacombe SJ, Marsh PD. Flow rates of resting whole and stimulated parotid saliva in relation to age and gender. J Dent Res. 1994; 73(8):1416-20. [PubMed: 8083437]

29. Ship JA, Pillemer SR, Baum BJ. Xerostomia and the geriatric patient. J Am Geriatr Soc. 2002; 50(3):535-43. [PubMed: 11943053]

30. Portman DJ, Gass ML. Vulvovaginal Atrophy Terminology Consensus Conference Panel. Genitourinary syndrome of menopause: new terminology for vulvovaginal atrophy from the International Society for the Study of Women's Sexual Health and the North American Menopause Society. Menopause. 2014; 21(10):1063-8. [PubMed: 25160739]

31. Maddali Bongi S, Del Rosso A, Orlandi M, et al. Gynaecological symptoms and sexual disability in women with primary Sjögren's syndrome and sicca syndrome. Clin Exp Rheumatol. 2013; 31(5):683-90. [PubMed: 23710558]

32. Bloch KJ, Buchanan WW, Wohl MJ, et al. Sjögren's Syndrome. a Clinical, Pathological, and Serological Study of Sixty-Two Cases. Medicine (Baltimore). 1965; 44:187-231. [PubMed: 14315274]

33. Sjögren H. Zur Kenntnis der Keratoconjunctivitis sicca (Keratitis filiformis bei Hypofunktion der Tränendrüsen). Acta Ophthalmol (Copenh). 1933; 11(Suppl 2):1-151.

34. Malladi AS, Sack KE, Shiboski SC, et al. Primary Sjögren's syndrome as a systemic disease: a study of participants enrolled in an international Sjögren's syndrome registry. Arthritis Care Res (Hoboken). 2012; 64(6):911-8. [PubMed: 22238244]

35. Theander E, Henriksson G, Ljungberg O, et al. Lymphoma and other malignancies in primary Sjögren's syndrome: a cohort study on cancer incidence and lymphoma predictors. Ann Rheum Dis. 2006; 65(6):796-803. [PubMed: 16284097]

36. Lin DF, Yan SM, Zhao Y, et al. Clinical and prognostic characteristics of 573 cases of primary Sjögren's syndrome. Chin Med J (Engl). 2010; 123(22):3252-7. [PubMed: 21163125]

37. Ramos-Casals M, Brito-Zeron P, Perez-De-Lis M, et al. Sjögren syndrome or Sjögren disease? The histological and immunological bias caused by the 2002 criteria. Clin Rev Allergy Immunol. 2010; 38(2-3):178-85. [PubMed: 19578996]

38. Ekstrom Smedby K, Vajdic CM, Falster M, et al. Autoimmune disorders and risk of non-Hodgkin lymphoma subtypes: a pooled analysis within the InterLymph Consortium. Blood. 2008; 111(8): 4029-38. [PubMed: 18263783]

39. Papageorgiou A, Ziogas DC, Mavragani CP, et al. Predicting the outcome of Sjögren's syndromeassociated non-hodgkin's lymphoma patients. PLoS One. 2015; 10(2):e0116189. [PubMed: 25723713]

40. Botsios C, Furlan A, Ostuni P, et al. Elderly onset of primary Sjögren's syndrome: clinical manifestations, serological features and oral/ocular diagnostic tests. Comparison with adult and 
young onset of the disease in a cohort of 336 Italian patients. Joint Bone Spine. 2011; 78(2):171-4. [PubMed: 20620090]

41. Ramos-Casals M, Solans R, Rosas J, et al. Primary Sjögren syndrome in Spain: clinical and immunologic expression in 1010 patients. Medicine (Baltimore). 2008; 87(4):210-9. [PubMed: 18626304]

42. Haga HJ, Jonsson R. The influence of age on disease manifestations and serological characteristics in primary Sjögren's syndrome. Scand J Rheumatol. 1999; 28(4):227-32. [PubMed: 10503559]

43. Baer AN, Medrano L, McAdams-DeMarco M, et al. Anti-centromere antibodies are associated with more severe exocrine glandular dysfunction in Sjögren's syndrome: Analysis of the Sjögren's International Collaborative Clinical Alliance cohort. Arthritis Care Res (Hoboken). 2016

44. Brito-Zeron P, Ramos-Casals M. EULAR-SS task force group. Advances in the understanding and treatment of systemic complications in Sjögren's syndrome. Curr Opin Rheumatol. 2014; 26(5): 520-7. [PubMed: 25050925]

45. Singh AG, Singh S, Matteson EL. Rate, risk factors and causes of mortality in patients with Sjögren's syndrome: a systematic review and meta-analysis of cohort studies. Rheumatology (Oxford). 2016; 55(3):450-60. [PubMed: 26412810]

46. Nannini C, Jebakumar AJ, Crowson CS, et al. Primary Sjögren's syndrome 1976-2005 and associated interstitial lung disease: a population-based study of incidence and mortality. BMJ Open. 2013; 3(11):e003569. 2013-003569.

47. Vitali C, Bombardieri S, Jonsson R, et al. Classification criteria for Sjögren's syndrome: a revised version of the European criteria proposed by the American-European Consensus Group. Ann Rheum Dis. 2002; 61(6):554-8. [PubMed: 12006334]

48. Shiboski SC, Shiboski CH, Criswell L, et al. American College of Rheumatology classification criteria for Sjögren's syndrome: a data-driven, expert consensus approach in the Sjögren's International Collaborative Clinical Alliance cohort. Arthritis Care Res (Hoboken). 2012; 64(4): 475-87. [PubMed: 22563590]

49. Rasmussen A, Ice JA, Li H, et al. Comparison of the American-European Consensus Group Sjögren's syndrome classification criteria to newly proposed American College of Rheumatology criteria in a large, carefully characterised sicca cohort. Ann Rheum Dis. 2014; 73(1):31-8. [PubMed: 23968620]

50. Cornec D, Jousse-Joulin S, Pers JO, et al. Contribution of salivary gland ultrasonography to the diagnosis of Sjögren's syndrome: toward new diagnostic criteria? Arthritis Rheum. 2013; 65(1): 216-25. [PubMed: 23108632]

51. Takagi Y, Sumi M, Nakamura H, et al. Ultrasonography as an additional item in the American College of Rheumatology classification of Sjögren's syndrome. Rheumatology (Oxford). 2014; 53(11):1977-83. [PubMed: 24907148]

52. Theander E, Mandl T. Primary Sjögren's syndrome: diagnostic and prognostic value of salivary gland ultrasonography using a simplified scoring system. Arthritis Care Res (Hoboken). 2014; 66(7):1102-7. [PubMed: 24339361]

53. Baldini C, Luciano N, Tarantini G, et al. Salivary gland ultrasonography: a highly specific tool for the early diagnosis of primary Sjögren's syndrome. Arthritis Res Ther. 2015; 17:146. 015-0657-7. [PubMed: 26022533]

54. Luciano N, Baldini C, Tarantini G, et al. Ultrasonography of major salivary glands: a highly specific tool for distinguishing primary Sjögren's syndrome from undifferentiated connective tissue diseases. Rheumatology (Oxford). 2015; 54(12):2198-204. [PubMed: 26206346]

55. Sun Z, Zhang Z, Fu K, et al. Diagnostic accuracy of parotid CT for identifying Sjögren's syndrome. Eur J Radiol. 2012; 81(10):2702-9. [PubMed: 22285605]

56. Takashima S, Takeuchi N, Morimoto S, et al. MR imaging of Sjögren syndrome: correlation with sialography and pathology. J Comput Assist Tomogr. 1991; 15(3):393-400. [PubMed: 2026798]

57. Satoh M, Chan EK, Ho LA, et al. Prevalence and sociodemographic correlates of antinuclear antibodies in the United States. Arthritis Rheum. 2012; 64(7):2319-27. [PubMed: 22237992]

58. Daniels TE, Cox D, Shiboski CH, et al. Associations between salivary gland histopathologic diagnoses and phenotypic features of Sjögren's syndrome among 1,726 registry participants. Arthritis Rheum. 2011; 63(7):2021-30. [PubMed: 21480190] 
59. Foulks GN, Forstot SL, Donshik PC, et al. Clinical guidelines for management of dry eye associated with Sjögren disease. Ocul Surf. 2015; 13(2):118-32. [PubMed: 25881996]

60. Costantino D, Guaraldi C. Effectiveness and safety of vaginal suppositories for the treatment of the vaginal atrophy in postmenopausal women: an open, non-controlled clinical trial. Eur Rev Med Pharmacol Sci. 2008; 12(6):411-6. [PubMed: 19146203]

61. Gottenberg JE, Ravaud P, Puechal X, et al. Effects of hydroxychloroquine on symptomatic improvement in primary Sjögren syndrome: the JOQUER randomized clinical trial. JAMA. 2014; 312(3):249-58. [PubMed: 25027140]

62. Kruize AA, Hene RJ, Kallenberg CG, et al. Hydroxychloroquine treatment for primary Sjögren's syndrome: a two year double blind crossover trial. Ann Rheum Dis. 1993; 52(5):360-4. [PubMed: 8323383]

63. Fox RI, Dixon R, Guarrasi V, et al. Treatment of primary Sjögren's syndrome with hydroxychloroquine: a retrospective, open-label study. Lupus. 1996; 5(Suppl 1):S31-6. [PubMed: 8803908]

64. Meijer JM, Meiners PM, Vissink A, et al. Effectiveness of rituximab treatment in primary Sjögren's syndrome: a randomized, double-blind, placebo-controlled trial. Arthritis Rheum. 2010; 62(4): 960-8. [PubMed: 20131246]

65. Devauchelle-Pensec V, Mariette X, Jousse-Joulin S, et al. Treatment of primary Sjögren syndrome with rituximab: a randomized trial. Ann Intern Med. 2014; 160(4):233-42. [PubMed: 24727841]

66. Carubbi F, Cipriani P, Marrelli A, et al. Efficacy and safety of rituximab treatment in early primary Sjögren's syndrome: a prospective, multi-center, follow-up study. Arthritis Res Ther. 2013; 15(5):R172. [PubMed: 24286296] 


\section{Box 1}

\section{Common causes of dry eye in the elderly}

$\begin{array}{ll}\text { Aqueous tear deficiency } & \text { Evaporative tear deficiency }\end{array}$

- Sjögren syndrome

- Meibomian gland dysfunction (posterior blepharitis)

- Age-related dry eye

- Exophthalmos, poor lid apposition, lid deformity

- Systemic medications (e.g. antihistamines, beta blockers, antispasmodics, diuretics)

- Low blink rate

- Lacrimal gland duct obstruction (e.g cicatricial pemphigoid, mucous membrane pemphigoid, trachoma, erythema multiforme, burns)

- Ocular sensory loss leading to reflex hyposecretion (e.g. diabetes mellitus, corneal surgery, contact lens - Low b

- Ocular surface disorders (e.g. vitamin A deficiency, toxicity from topical drugs/ preservatives, contact lens wear)

wear, trigeminal nerve injury)

- Ocular surface disease (e.g. allergic conjunctivitis)

- Lacrimal gland infiltration (e.g. sarcoid, lymphoma,

graft vs host disease, AIDS, IgG4-related disease) 


\section{Box 2}

Tests used to assess dry eye disease

\begin{tabular}{|lll|}
\hline Test & Abnormal value & Significance of abnormal test \\
\hline Schirmer & $<5 \mathrm{~mm} / 5$ minute in either eye & Inadequate tear production \\
Ocular surface staining & $\begin{array}{l}\text { Score } \geq 4 \text { (van Bijsterveld) } \\
{[18] \text { Score } \geq 3 \text { (SICCA) [19] }}\end{array}$ & Damage to the ocular surface \\
Tear break up time & $<10$ seconds & $\begin{array}{l}\text { Poor tear film stability, as seen in } \\
\text { meibomian gland dysfunction }\end{array}$ \\
Tear osmolarity & $2308 \mathrm{mOsm} / \mathrm{L}$ in either eye & $\begin{array}{l}\text { Excessive tear evaporation, lacrimal gland } \\
\text { disease, or ocular surface inflammation }\end{array}$ \\
\hline
\end{tabular}

Data from van Bijsterveld OP. Diagnostic tests in the Sicca syndrome. Arch Ophthalmol 1969;82(1):10-4; and Whitcher JP, Shiboski CH, Shiboski SC et al. A simplified quantitative method for assessing keratoconjunctivitis sicca from the Sjögren's Syndrome International Registry. Am J Ophthalmol 2010;149(3): 405-15. 


\section{Box 3}

\section{Measurement of unstimulated whole salivary flow rate}

Unstimulated whole saliva collection measures saliva production under resting or basal conditions. The subject should not have had anything to eat or drink for 90 minutes before the procedure. The use of a

parasympathomimetic should be discontinued for 12 hours before the procedure, and the use of artificial salivas should be stopped 3 hours prior. During the collection procedure, the subject is instructed to minimize actions that can stimulate saliva (talking, increased orofacial movement) and should not swallow. At time " 0 ," any saliva present in the mouth is cleared by swallowing. For the subsequent 5 minutes, any saliva collected in the mouth is emptied into a preweighed tube every minute (i.e., five times). This collecting tube then is weighed to determine a postcollection weight. The difference between the pre- and postcollection weight is determined, and this represents the unstimulated whole saliva production for 5 minutes. To convert to a volume of saliva from the weight of saliva, an assumption is made that saliva is similar to water, where $1 \mathrm{~g}$ of water/saliva at $4^{\circ} \mathrm{C}$ equals $1 \mathrm{~mL}$ of saliva/water.

Less than $0.100 \mathrm{~mL} / \mathrm{min}$ is considered a reduced unstimulated salivary flow rate.

From Wu AJ. Optimizing dry mouth treatment for individuals with Sjögren's syndrome. Rheum Dis Clin North Am. 2008 Nov;34(4):1001-10; with permission. 
Box 4

\section{Common causes of dry mouth in the elderly}

- Medications, including anti-depressants, anti-cholinergics, anti-spasmodics, anti-

hypertensives, antihistamines, sedatives and diuretics

- $\quad$ Sjögren syndrome

- $\quad$ Diabetes mellitus

- Head and neck irradiation

- Dehydration

- $\quad$ Parkinson's disease 


\section{Box 5}

\section{Key clinical features of Sjögren syndrome}

- $\quad$ Predominant involvement of women, with female to male ratios over 10:1.

- Diagnosis most commonly established in the fifth and sixth decade of life, although symptoms of dryness may precede the diagnosis by many years.

- $\quad$ Affects individuals across the age spectrum, including children, but most commonly women in the perimenopausal years of life

$\bullet$

"Extraglandular" manifestations in approximately $50 \%$ of patients, including constitutional symptoms (such as fatigue and mild cognitive impairment) and other systemic manifestations, with involvement of diverse organ systems.

$\bullet$

Presence of anti-SSA (Ro) and anti-SSB (La) in $60-80 \%$ of patients [34-37].

- Increased risk of B-cell non-Hodgkin lymphoma, particularly mucosa-associated lymphoid tissue lymphoma (MALT) and diffuse B-cell lymphoma. The relative risk of non-Hodgkin lymphoma ranges from 4.8 for primary and 9.6 for secondary SS [38], with an estimated lifetime risk of 5-10\% [39].

Data from Refs 34-39 


\section{Box 6}

\section{Modes of presentation of Sjögren syndrome}

-
Eymptoms or signs of dry eyes and mouth
-
Eudden increase in dental caries
An established connective tissue disease complicated by dry eyes or mouth
Extraglandular disease (such as annular erythema, cryoglobulinemia, peripheral
neuropathy, or interstitial pneumonitis)
Abnormal serologic test, such as anti-SSA and/or anti-SSB antibodies
MALT lymphoma of a salivary gland




\section{Box 7}

\section{Systemic manifestations of Sjögren's syndrome}

\begin{tabular}{|c|c|}
\hline Organ-involvement & Manifestation \\
\hline \multirow[t]{2}{*}{ Constitutional } & Fatigue \\
\hline & Mild cognitive disturbance \\
\hline \multirow[t]{2}{*}{ Musculoskeletal } & Arthritis/arthralgia \\
\hline & Myositis (especially inclusion body myositis) \\
\hline \multirow[t]{3}{*}{ Cutaneous } & Annular erythema \\
\hline & Xerosis \\
\hline & Palpable purpura \\
\hline \multirow[t]{2}{*}{ Pulmonary } & Interstitial pneumonitis \\
\hline & Follicular bronchiolitis \\
\hline \multirow[t]{2}{*}{ Vascular } & Raynaud's \\
\hline & Vasculitis \\
\hline \multirow[t]{2}{*}{ Gastrointestinal } & Atrophic gastritis \\
\hline & Primary biliary cirrhosis \\
\hline Endocrine & Autoimmune thyroid disease \\
\hline Cardiac & Pericarditis \\
\hline \multirow[t]{2}{*}{ Renal } & Interstitial nephritis with renal tubular acidosis \\
\hline & Membranoproliferative glomerulonephritis \\
\hline \multirow[t]{5}{*}{ Hematologic } & Leucopenia, neutropenia \\
\hline & Thrombocytopenia \\
\hline & Anemia \\
\hline & Monoclonal gammopathy \\
\hline & Cryoglobulinemia \\
\hline Lymphoproliferative & Lymphoma \\
\hline \multirow[t]{3}{*}{ Neurologic } & Peripheral neuropathy \\
\hline & Ataxic ganglionopathy \\
\hline & Myelitis (including neuromyelitis optica) \\
\hline
\end{tabular}


Box 8

\section{American-European Consensus Group Revised International Classification Criteria for Sjögren's Syndrome}

1

cular symptoms: a positive response to at least one of the following questions:

1.

2.

3.

Have you had daily, persistent, troublesome dry eyes for more than 3 months?

Do you have a recurrent sensation of sand or gravel in the eyes?

2

Oral symptoms: a positive response to at least one of the following questions:

1.

Have you had a daily feeling of dry mouth for more than 3 months?

2. Have you had recurrently or persistently swollen salivary glands as an adult?

3

Do you frequently drink liquids to aid in swallowing dry food?

Ocular signs - objective evidence of ocular involvement defined as a positive result for at least one of the following two tests:

1.

Schirmer's test, performed without anaesthesia ( $<5 \mathrm{~mm}$ in $5 \mathrm{~min})$

2.

Rose Bengal score or other ocular dye score ( $>4$ according to van Bijsterveld's scoring system)

Histopathology: In minor salivary glands (obtained through normal-appearing mucosa) focal lymphocytic sialoadenitis, evaluated by an expert histopathologist, with a focus score $>1$, defined as a number of lymphocytic foci (which are adjacent to normalappearing mucous acini and contain more than 50 lymphocytes) per $4 \mathrm{~mm}^{2}$ of glandular tissue

5

Salivary gland involvement: objective evidence of salivary gland involvement defined by a positive result for at least one of the following diagnostic tests:

1.

Unstimulated whole salivary flow $(<1.5 \mathrm{~mL}$ in $15 \mathrm{~min})$

2.

Parotid sialography showing the presence of diffuse sialectasias (punctate, cavitary or destructive pattern), without evidence of obstruction in the major ducts

3. Salivary scintigraphy showing delayed uptake, reduced concentration and/or delayed excretion of tracer

6

Autoantibodies: presence in the serum of the following autoantibodies:

1.

Antibodies to $\mathrm{Ro}(\mathrm{SSA})$ or $\mathrm{La}(\mathrm{SSB})$ antigens, or both

For primary $S S$

In patients without any potentially associated disease, primary SS may be defined as follows:

a.

The presence of any 4 of the 6 items is indicative of primary SS, as long as either item IV (Histopathology) or VI (Serology) is positive

b.

The presence of any 3 of the 4 objective criteria items (that is, items III, IV, V, VI)

c. The classification tree procedure represents a valid alternative method for classification, although it should be more properly used in clinical-epidemiological survey

For secondary $S S$

In patients with a potentially associated disease (for instance, another well-defined connective tissue disease), the presence of item I or item II plus any 2 from among items III, IV, and V may be considered as indicative of secondary SS

Exclusion criteria: Past head and neck radiation treatment; hepatitis $\mathrm{C}$ infection; acquired immunodeficiency disease (AIDS); pre-existing lymphoma; sarcoidosis; graft versus host disease; use of anticholinergic drugs (since a time shorter than 4-fold the half-life of the drug)

Clin Geriatr Med. Author manuscript; available in PMC 2018 February 01 
From Vitali C, Bombardieri S, Jonsson R et al. Classification criteria for Sjögren's syndrome: a revised version of the European criteria proposed by the American-European Consensus Group. Ann Rheum Dis 2002;61(6): 554-8; with permission. 


\section{Box 9}

\section{American College of Rheumatology Provisional Criteria for Classification of Sjögren's Syndrome}

The classification of SS, which applies to individuals with signs/symptoms that may be suggestive of SS, will be met in patients who have at least 2 of the following 3 objective features:

1

Positive serum anti-SSA/Ro and/or anti-SSB/La or (positive rheumatoid factor and ANA titer $\geq 1: 320$ )

2

Labial salivary gland biopsy exhibiting focal lymphocytic sialadenitis with a focus score $\geq 1$ focus $/ 4 \mathrm{~mm}^{2}$

3

Keratoconjunctivitis sicca with ocular staining score $\geq 3$ (assuming that individual is not currently using daily eye drops for glaucoma and has not had corneal surgery or cosmetic eyelid surgery in the last 5 years

Prior diagnosis of any of the following conditions would exclude participation in SS studies or therapeutic trials because of overlapping clinical features or interference with criteria tests:
$\cdot$
-
History of head and neck radiation treatment
Hepatitis C infection
- $\quad$ Acquired immunodeficiency syndrome
- Sarcoidosis
- $\quad$ Amyloidosis
- Graft versus host disease
-
IgG4-related disease

From Shiboski SC, Shiboski CH, Criswell L et al. American College of Rheumatology classification criteria for Sjögren's syndrome: a data-driven, expert consensus approach in the Sjögren's International Collaborative Clinical Alliance cohort. Arthritis Care Res (Hoboken) 2012;64(4):475-87; with permission. 


\section{Key points}

- $\quad$ Symptoms of dry eyes and dry mouth are common in the elderly and most often relate to medication side effects.

- $\quad$ Sjögren syndrome is the prototypic illness that causes dry eyes and dry mouth and is an important diagnostic consideration in older individuals presenting with dry eye and mouth symptoms.

- $\quad$ The diagnosis of Sjögren syndrome requires the presence of anti-SSA and/or anti-SSB antibodies, or a minor salivary gland biopsy demonstrating at least one tightly-aggregated periductal lymphocytic aggregate per 4 square millimeter of glandular tissue section (focal lymphocytic sialadenitis with a focus score $\geq 1$ ).

- Management of Sjögren syndrome requires attention to both the glandular (ocular and oral dryness, glandular enlargement) and extraglandular manifestations (e.g. arthritis, pneumonitis, nephritis, vasculitis). 


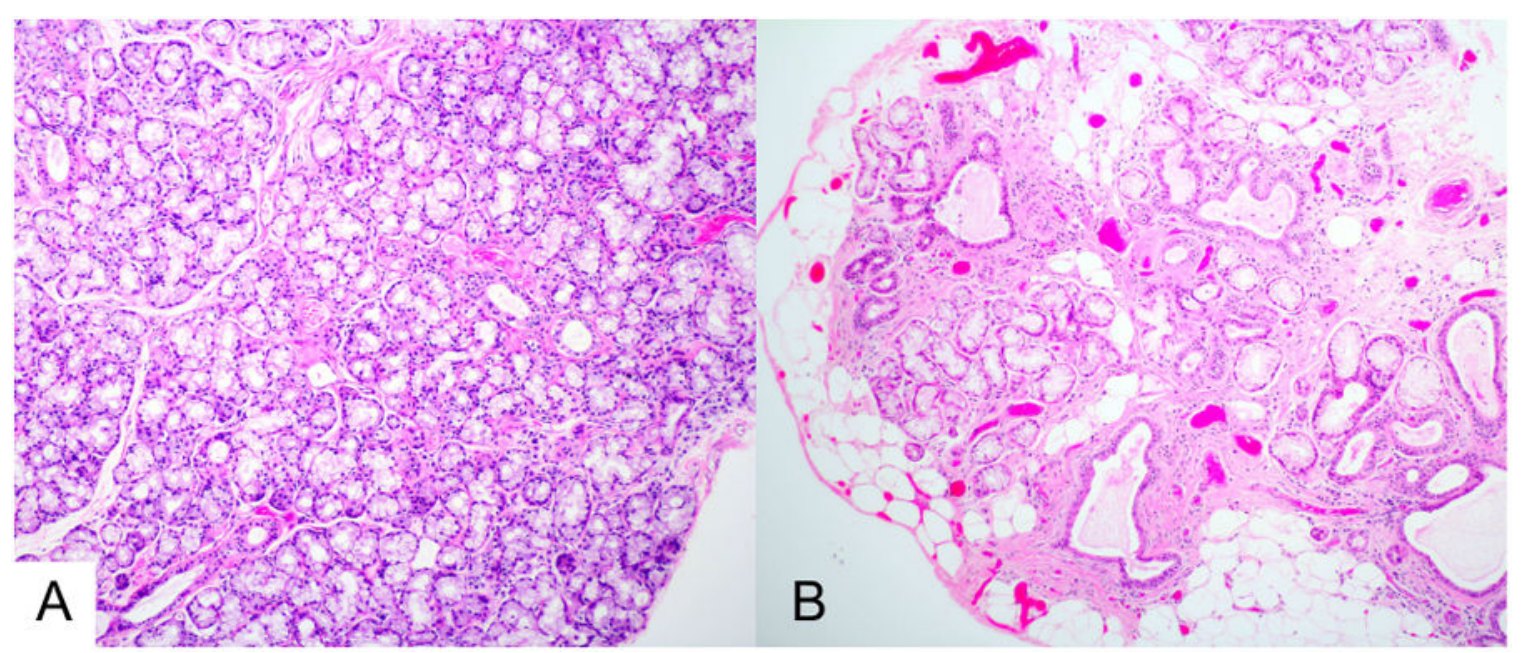

Figure 1.

Histopathology of minor labial salivary glands. The sections are from biopsies of a 28 yearold woman (panel A) and a 65 year-old woman (panel B), shown at the same magnification. The histopathologic section in panel A shows normal tissue, with confluent mucous acini and normal-sized intralobular ducts. In contrast, the section in panel B shows extensive acinar loss, interstitial fibrosis, ductal dilatation, and fatty replacement. The changes in panel $\mathrm{B}$ are often seen to varying degree in older patients. (Magnification $100 \times$ ) 

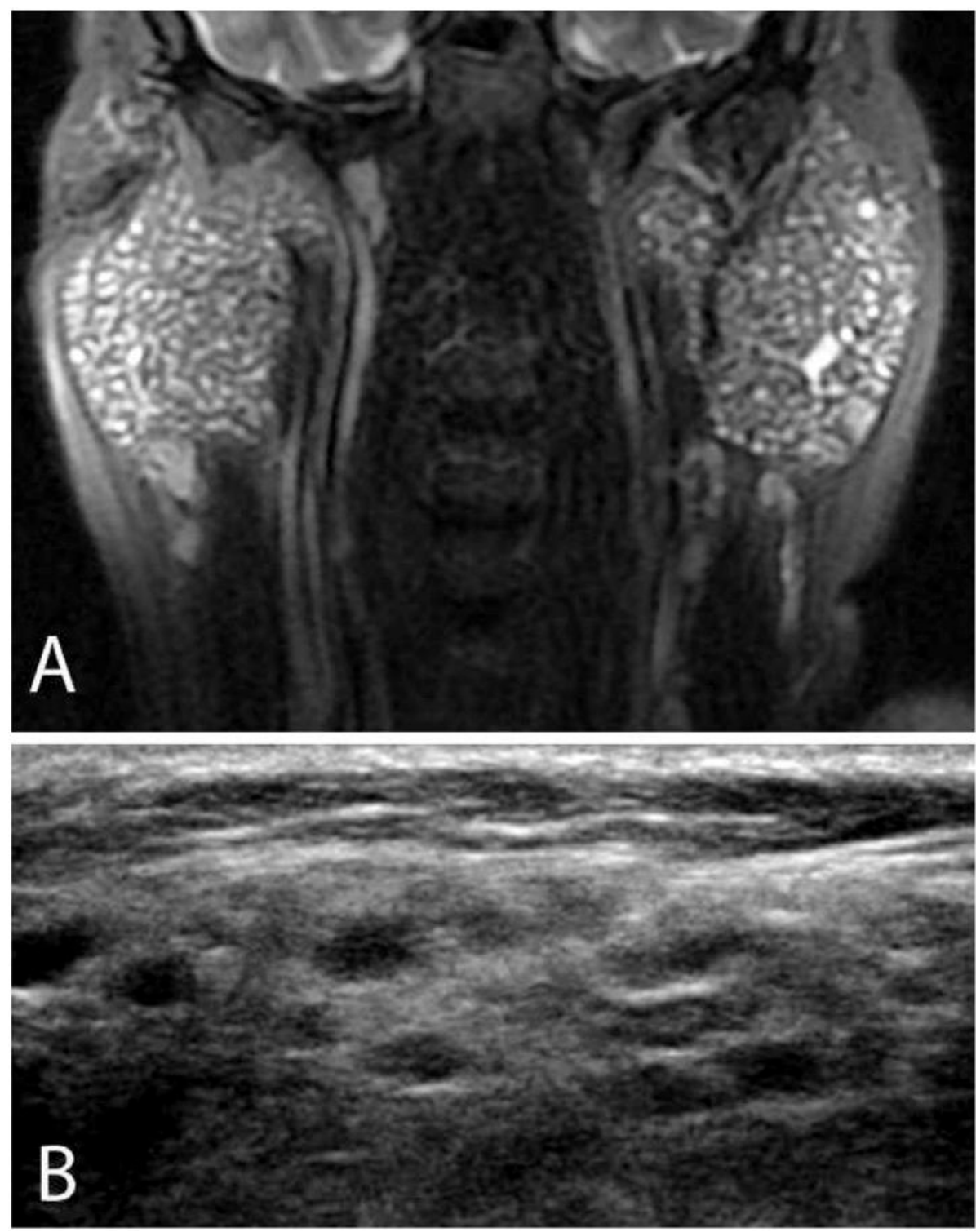

Figure 2.

Imaging techniques in Sjögren's syndrome. This patient has bilateral symmetric parotid gland enlargement, seen best on the T2 fat-suppressed magnetic resonance images (panel A). Note the multiple T2-hyperintense foci scattered throughout both glands, a characteristic finding. With ultrasonography (panel B), multiple hypoechoic rounded lesions with convex borders are noted throughout the glandular parenchyma. In normal parotid gland tissue, the parenchyma has a homogeneous appearance with ultrasonography. 


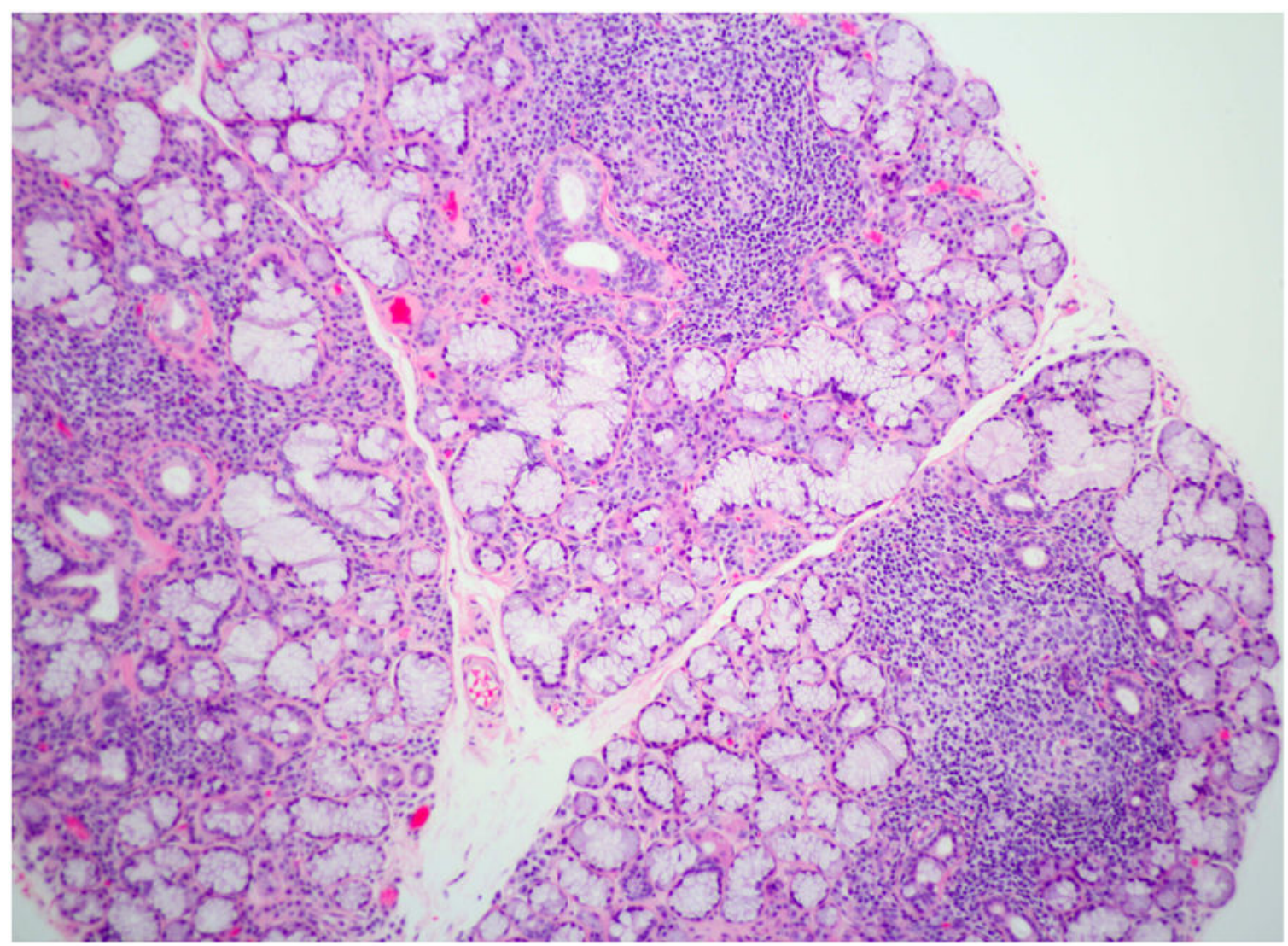

Figure 3.

Focal lymphocytic sialadenitis. This section of a labial minor salivary gland biopsy shows the typical features of focal lymphocytic sialadenitis. Note the tightly aggregated lymphocytes surrounding ducts and adjacent to normal-appearing mucous acini. At least three foci are evident in this photomicrograph. (Magnification 100x). 

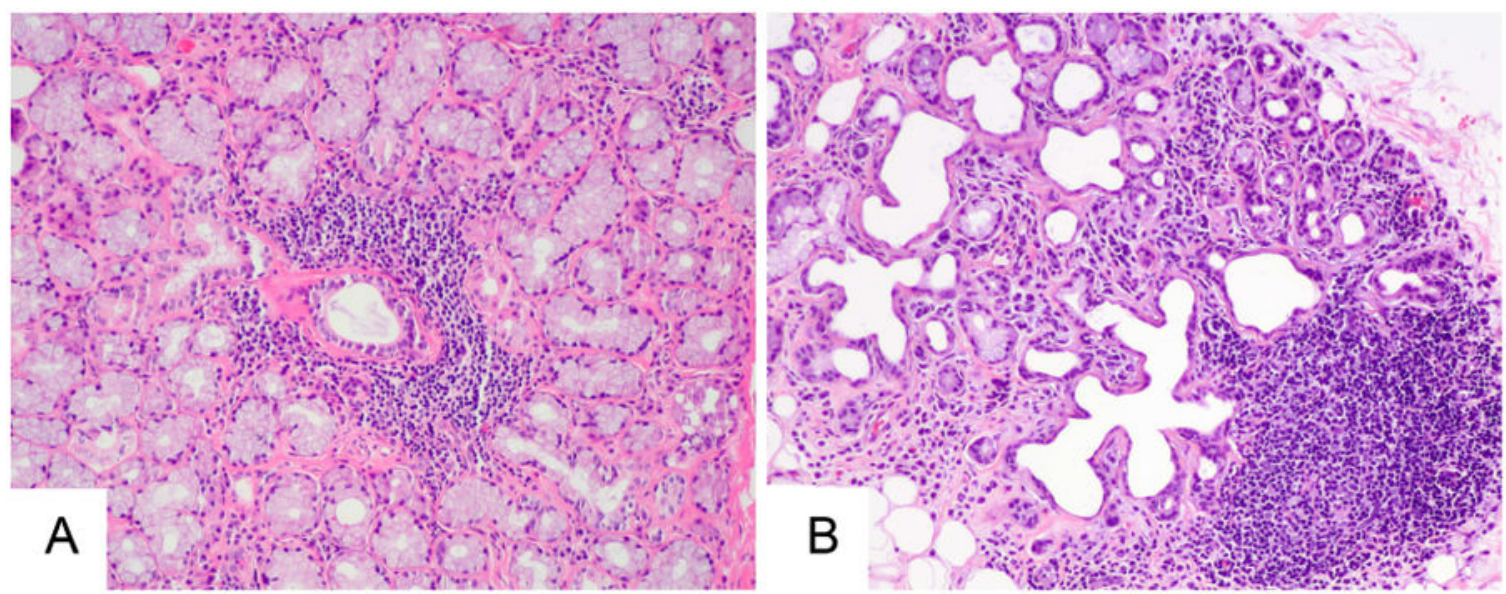

Figure 4.

Potential misinterpretation of labial gland biopsies. The lymphocytic focus in the panel A is typical of that seen in focal lymphocytic sialadenitis, being centered around a duct and adjacent to normal-appearing mucous-secreting acini. In contrast, the lymphocytic focus in panel B is present within a gland lobule marked by interstitial fibrosis, ductal dilatation, and marked acinar loss. This focus should not be interpreted as representative of Sjögren's syndrome, (Magnification 100x). 